\title{
MELANOMA INVASION IN THE MOUSE UTERUS
}

\author{
I. B. WILSON AND D. M. POTTS* \\ Department of Zoology, University College of North Wales, Bangor, Caernarvonshire, and \\ Department of Anatomy, University of Cambridge
}

(Received 5th Fune 1969)

\begin{abstract}
Summary. The passage of melanoma cells into the subepithelial tissues of a pseudopregnant mouse uterus was studied at the electron microscope level. A suspension of cells, injected through the cervix, was rapidly distributed along the length of the uterus. Within $\frac{1}{2}$ to $1 \mathrm{hr}$ after transfer, the melanoma cells began to establish a close relationship with the uterine epithelium. In limited areas, the passage of melanoma cells between (and possibly through) epithelial cells was observed within $1 \mathrm{hr}$ of transfer. By $4 \mathrm{hr}$ after transfer, large islands of melanoma cells were present beneath the uterine epithelium in antimesometrial areas of the uterus. No decidual changes were apparent. The ultrastructural changes seen in the maternal cells were similar to those in the initial stages of blastocyst implantation, but the melanoma cells behaved as individual units and passed through the epithelium more rapidly, and with less destruction, than trophoblast.
\end{abstract}

\section{INTRODUCTION}

The fate of malignant tissues transplanted into the uterus of laboratory rodents, under various hormonal conditions, has been studied by several workers (Mohs \& Guyer, 1937; Hall, 1940; Homburger, Treigier \& Grossman, 1956; Wilson, 1960, 1963; Stein-Werblowsky, 1961; Schlesinger, 1962; Short \& Yoshinaga, 1967). All the reports to date have been based on light microscope observations. In the mouse, melanoma cells only invade the uterine tissues under conditions which parallel those when normal implantation will take place, though the mechanisms facilitating invasion are not known. The aim of the present investigation was to extend the study of the process of invasion (Wilson, 1963) to the electron microscope level in the hope that this would elucidate some of the morphological processes involved. Melanoma cells are particularly suitable for this work because they are readily identifiable under the light and electron microscope.

\section{MATERIALS AND METHODS}

The techniques used in the transfer of melanoma to the uterus were as previously described (Wilson, 1963). A small volume of melanoma cell suspension

* Present address: International Planned Parenthood Federation, 18-20 Lower Regent Street, London, S.W.1. 
was inserted through the cervix into the uterus of twelve mice on the 5th day of pseudo-pregnancy (approximately $100 \mathrm{hr}$ after mating). At intervals from 30 min to $4 \mathrm{hr}$ after transfer, the uteri were removed, fixed in cold, buffered gluteraldehyde and later post-osmicated. Melanoma tissue was also placed directly in buffered osmium fixative for comparative observations.

Electron microscope material from six mice was serially sectioned at $80 \mu$ in celloidin and embedded in Araldite. Sections containing melanoma cells were selected with the light microscope and then re-sectioned on the ultramicrotome (Potts, 1966). Electron microscope sections were double stained with lead citrate and uranyl acetate and viewed at a magnification of $\times 1000$ to $\times 14,000$.

\section{OBSERVATIONS}

\section{Melanoma cells}

These cells were easily distinguished by their prominent pigment granules. The plasma membrane was poorly defined, the nucleus was ovoid with a patchy distribution of RNA granules. Mitoses were rare, but degenerating cells with membrane-bound vacuoles, free pigment granules and pale vacuolated nuclei, were common. There was no difference in the ultrastructure of melanoma cells before or after transplantation, whether they were free in the uterine lumen or buried in the uterine tissues.

\section{Uterine epithelium}

The epithelial cells were rectangular in shape, the nuclei lay towards the basal end of the cell and lipid droplets were mainly present below the nucleus although a minority was found above it. The luminal surface of the cells was thrown up into irregular microvilli and bulbous processes. The cells rested on a sinuous basement membrane. Leucocytes were found among the stromal cells, especially immediately beneath the basement membrane of the uterine epithelium.

\section{Tumour invasion at $\frac{1}{2}$ to $1 \mathrm{hr}$ after transfer}

Clumps of melanoma cells were found in the uterine lumen within $30 \mathrm{~min}$ of transfer on the 5th day of pseudopregnancy. These cells established a close contact with the epithelial cells, their plasma membranes resting on the tops of the microvilli. When, because of shrinkage during fixation, the two groups of cells pulled apart at the line of contact, fragments of melanoma cells might remain attached to the epithelium.

Pocketing of the epithelial cell surface took place occasionally, forming cuplike depressions 10 to $15 \mu$ across, enclosing melanoma cells and fragments of

\section{EXPLANATION OF PLATE 1}

FIG. 1. Melanoma cells (m) passing between uterine epithelial cells (e) 30 min after transfer. Note the lack of regular microvilli in the epithelial cells near the site of invasion (arrows). The uterine lumen contains melanoma cells and fragments of melanoma cells. $\times 5300$.

Fig. 2. Melanoma cells (m) under the uterine epithelium (e) $3 \mathrm{hr}$ after transfer. Small clumps of pigment granules are present (arrows) in one epithelial cell. $\times 5300$. 
PLATE 1

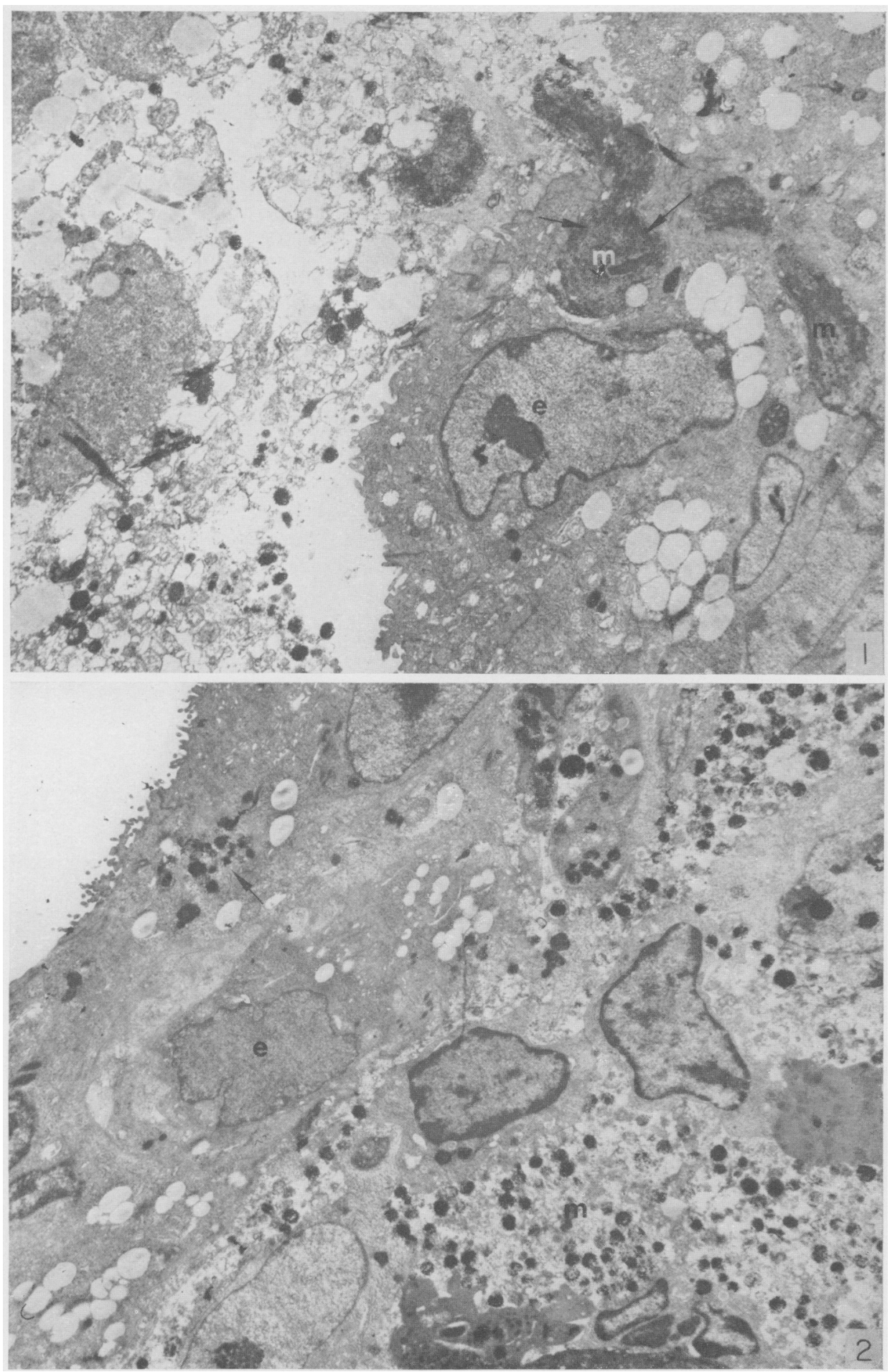

(Fuing p. 430) 
cells. Sometimes this change was associated with a flattening of the maternal microvilli.

Three examples of melanoma cells penetrating the maternal epithelium between $\frac{1}{2}$ and $1 \mathrm{hr}$ after transfer were found. Over the limited area involved, the microvilli on the epithelial cells were flattened and the plasma membranes of the melanoma cells and maternal cells were intimately related (Pl. 1, Fig. 1). Melanoma cells were present both between adjacent epithelial cells and engulfed by cytoplasm of a single epithelial cell. The nuclei of the invading cells were found at the point of maximum penetration and were compressed laterally.

\section{Tumour invasion 3 to $4 \mathrm{hr}$ after transfer}

The remaining clumps of melanoma cells were spaced out along the uterus distending the uterine lumen and sometimes flattening the epithelium, but the bulk of the transferred tumour was in the uterine stroma beneath the epithelium. The melanoma cells which had invaded were arranged in islands of many thousands of cells and these islands were always found in the antimesometrial third of the uterus. There was a high proportion of degenerating cells amongst the melanoma cells in the uterine lumen and leucocytes were commonly present, often containing phagocytosed pigment granules. The islands of tumour cells in the stromal tissue formed compact units and isolated melanoma cells were not found, although, near the periphery of an island, there would be some mingling of malignant and maternal cells. Melanoma cells were often found packed beneath the uterine epithelium and sometimes the epithelium was lifted off the underlying stromal tissue by the mass of malignant cells. Either the basement membrane of the uterine epithelium re-formed over the melanoma cells or, when extending laterally from the site of the invasion, the cells halted at the under surface of the basement membrane (Pl. 1, Fig. 2).

Sometimes pigment granules from the melanoma cells could be identified in the stromal cells; usually these were in membrane-bound pockets. Leucocytes were commonly present in relation to the tumour and were found both mixed with the melanoma cells and forming well-defined palisades at the edge of an invading island. Polymorphonuclear leucocytes were most common and eosinophils were sometimes present. Plasma cells, however, have not been identified.

Three hours after transplantation, only isolated evidence remained of the penetration of the uterine epithelium by the body of malignant cells. Melanoma cells were sometimes found closely related to the surface of the epithelium but without any alteration in the morphology of the luminal plasma membrane. Very occasionally, small areas of cytoplasm, packed with melanoma granules, were found among the epithelial cells.

\section{DISCUSSION}

The following interpretation of the histological findings is offered. The transplanted melanoma cells are spaced into clumps along the length of the uterus. The tumour cells migrate across the epithelium and perhaps occasionally through the epithelial cells. The process appears to take place rapidly and with little or no damage to the maternal cells. The melanoma cells collect in clumps 
in the antimesometrial stromal tissue. In the first $4 \mathrm{hr}$ after transfer, there are no visible signs of a decidual reaction but there is a migration of leucocytes towards the site of tumour invasion and into the clumps of melanoma cells that remain in the uterine lumen.

The technique of transferring the tumour to the uterus cannot directly damage the epithelium nor does it seem likely that the Tyrode solution, used for the cell suspension, would introduce artifacts.

The process of tumour invasion has some similarities with and some differences from, blastocyst invasion. The parallel in timing and gross morphology between blastocyst implantation and melanoma invasion in the mouse has been pointed out by Wilson (1963) and the similarity between experimental implantation in spayed rats maintained on exogenous hormones and the invasion of Walker carcino-sarcoma has been established by Short \& Yoshinaga (1967). The hormonal background of nidation in rodents is partly understood and some of the ultrastructural prerequisites of blastocyst attachment and invasion have been defined (Mayer, Nilsson \& Reinius, 1967; Enders \& Schlafke, 1967). In the spayed rat maintained on progesterone, the attachment of the blastocyst can be delayed until a minute dose of oestrogen $(0 \cdot 1 \mu \mathrm{g}$ oestradiol$17 \beta)$ is given. At the ultrastructural level, three phases can be identified:

(1) a pre-attachment phase, when the epithelial cells have a regular villous border,

(2) an attachment phase, when the border of the uterine cells becomes serpentine with irregular processes, and

(3) an adherence phase, when, at the implantation site, the maternal plasma membranes become completely flattened and intimately related to the overlying trophoblast.

These changes take place approximately 18 to $24 \mathrm{hr}$ after the implanting dose of oestrogen (Potts, 1969). Morphologically similar changes occur in the mouse, hamster and possibly in Microchiroptera (Racey, personal communication) and appear to be a prerequisite for epithelial destruction and the invasion of the maternal tissues by the trophoblast. Trophoblast invasion occurs as a result of penetration between, and phagocytosis of, epithelial cells.

In the present experiments, the melanoma cells were transplanted at a time when the plasma membrane of the uterine epithelial cells had transformed to an irregular surface (attachment phase) and was in a physiologically receptive state. The melanoma cells, however, do not imitate the adherent phase of implantation, unless it is for a very brief interval during the period the tumour cells are migrating across the epithelium. During normal implantation, the adherent phase persists for several hours and tongues of trophoblast can be found dipping down between the epithelial cells but not reaching the basement membrane (Potts, 1968). One explanation of the difference in behaviour between the tumour cells and the blastocyst could be that the trophoblast cells are united by tight junctions presenting a continuous front which is adherent to the surface of a large number of maternal cells, while the melanoma cells are separate and each one behaves as a single unit, rapidly migrating between the epithelial cells. Melanoma cells can be found migrating between epithelial 
cells, but sometimes a portion of a migrating cell can be found encircled by the cytoplasm of a single epithelial cell. Such a situation could arise as a result of sectioning an irregular interface between two cells, or it could demonstrate the ability of a melanoma cell to indent the luminal plasma membrane of an epithelial cell and possibly create a passage through the cell. Collections of melanoma granules in membrane-bound pockets of epithelial cell cytoplasm 3 to $4 \mathrm{hr}$ after transfer may arise as the result of migration, or attempted migration, through epithelial cells. Leucocytes can migrate through the uterine epithelium from below upwards and the ultrastructural details of the process appear to be very similar to melanoma invasion, though differing in polarity and in involving genetically identical cells.

We suggest that the regular microvillous border of the uterine epithelial cells found in the absence of oestrogen is resistant to tumour invasion and unsuitable for blastocyst attachment. The changes which take place in the epithelial cells in response to oestrogen predispose to blastocyst attachment and permit migration of the melanoma cells through the epithelium but without any large scale disruption of the epithelium. The passage of the tumour is rapid and virtually complete within $3 \mathrm{hr}$ of transplanting the tumour.

In view of the nature of attachment of melanoma cells to the epithelium and the subsequent invasion of the stroma, it seems remarkable that this does not result in the formation of decidual tissue (see Wilson, 1963). A variety of nonspecific stimuli can evoke the decidual reaction and one would expect melanoma invasion to provide sufficient stimulus. It certainly provokes a strong inflammatory response. Some experimental stimuli of the decidual reaction, such as oils (Finn \& Hinchcliffe, 1964), may possess features which mimic the action of the blastocyst; others, such as sutures, may simply bypass the normal pathway because of their crude traumatic effect. The pattern of activity of melanoma cells in the uterus imitates that of the trophoblast quite closely and it may be that, although they follow a similar pathway, the specific characteristic of trophoblast which induces the decidual reaction is missing from melanoma cells.

Perhaps this specific characteristic resides in the arrangement of the trophoblast cells into a cohesive sheet, whereas the melanoma cells act more as discrete individuals. Certainly, the surface properties of the melanoma cells appear to be sufficiently compatible with those of the epithelium to enable proper attachment and penetration to occur. Such compatibility of surfaces seems vital to this process as rat blastocysts in the mouse uterus are not able to attach to and penetrate the epithelium adequately to ensure survival (Potts, Wilson \& Smith, 1970).

\section{ACKNOWLEDGMENTS}

This research was partly supported by a grant from the Medical Research Council. We are grateful to Mrs S. Barton for her assistance at all stages of the work.

\section{REFERENCES}

Enders, A. C. \& Schlafke, S. (1967) A morphological analysis of the early implantation stages in the rat. Am. F. Anat. 120, 185. 
FiNN, C. A. \& HINCHCLIFFE, J. R. (1964) Reaction of the uterus during implantation and deciduoma formation as demonstrated by changes in the distribution of alkaline phosphatase. $\mathcal{F}$. Reprod. Fert. 8, 331 .

HALL, B. V. (1940) Influence of the estrus cycle and the decidual reaction on transplanted intrauterine tumours in mice. Yale 7. Biol. Med. 13, 333.

Homburger, F., Treigier, A. \& Grossman, M. S. (1956) Tumour growth in hormone-susceptible sites. Comparison of tumour growth and hormonal effects in rodents' uteri and other sites. Cancer Res. 16, 106.

MAyer, G., Nilsson, O. \& Rerntus, S. (1967) Cell membrane changes of uterine epithelium and trophoblasts during blastocyst attachment in rat. Z. Anat. EntwGesch. 126, 43.

MOHs, F. E. \& GUYER, M. F. (1937) Response of the rat endometrium to cancer grafts. Anat. Rec. 69, 197.

Potrs, D. M. (1968) The ultrastructure of implantation in the mouse. F. Anat. 103, 77.

PotTs, D. M., WiLson, I. B. \& SMTth, M. S. R. (1970) Observations in rat eggs transplanted to the mouse uterus. F. Reprod. Fert. $22,425$.

Potrs, M. (1966) A method for locating specific histological features for electron microscopy. $\mathcal{F l ~} R$. microsc. Soc. 85, 97.

Potrs, M. (1969) The ultrastructure of egg implantation. In: Advances in Reproductive Physiology, Vol. 4, p. 241. Ed. A. McLaren. Logos Press, London.

Schlesinger, M. (1962) Uterus of rodents as site for manifestation of transplantation immunity against transplantable tumours. $\mathcal{F}$. natn. Cancer Inst. 28, 927.

SHort, R. V. \& YoshinaGA, K. (1967) Hormonal influences on tumour growth in the uterus of the rat. F. Reprod. Fert. 14, 287.

Stein-Werblowsky, R. (1961) Tumour inhibition during gestation. 7. Obstet. Gynaec. Br. Commonw. 68, 498.

WiLson, I. B. (1960) Implantation of tissue transplants in the uteri of pseudopregnant mice. Nature, Lond. 185, 553.

Wilson, I. B. (1963) A tumour tissue analogue of the implanting mouse embryo. Proc. zool. Soc. Lond. 141, 137. 